\title{
Depression Quality of Care: Measuring Quality over Time Using VA Electronic Medical Record Data
}

\author{
Melissa M. Farmer, $P h D^{7}$, Lisa V. Rubenstein, MD, MSPH 1,2,3, Cathy D. Sherbourne, PhD', \\ Alexis Huynh, PhD, $\mathrm{MPH}^{7}$, Karen Chu, MS ${ }^{7}$, Christine A. Lam, MD, MBA' , Jacqueline J. Fickel, PhD' , \\ Martin L. Lee, $P h D^{1,3}$, Maureen E. Metzger, PhD, MPH', Lilia Verchinina, $P h D^{4}$, \\ Edward P. Post, MD, PhD ${ }^{4,5}$, and Edmund F. Chaney, PhD
}

'VA HSR\&D Center for the Study of Healthcare Innovation, Implementation \& Policy, VA Greater Los Angeles Healthcare System, Sepulveda, CA, USA; ${ }^{2}$ RAND, Santa Monica, CA, USA; ${ }^{3}$ David Geffen School of Medicine and Fielding School of Public Health, University of California, Los Angeles, CA, USA; ${ }^{V}$ VA Ann Arbor, HSR\&D Center for Clinical Management Research, Ann Arbor, MI, USA; ${ }^{5}$ University of Michigan Medical School, Ann Arbor, MI, USA; ${ }^{\circ}$ University of Washington School of Medicine, Seattle, WA, USA.

\begin{abstract}
BACKGROUND: The Veterans Health Administration (VA) has invested substantially in evidence-based mental health care. Yet no electronic performance measures for assessing the level at which the population of Veterans with depression receive appropriate care have proven robust enough to support rigorous evaluation of the VA's depression initiatives.
\end{abstract}

OBJECTIVE: Our objectives were to develop prototype longitudinal electronic population-based measures of depression care quality, validate the measures using expert panel judgment by VA and non-VA experts, and examine detection, follow-up and treatment rates over a decade (2000-2010). We describe our development methodology and the challenges to creating measures that capture the longitudinal course of clinical care from detection to treatment.

DESIGN AND PARTICIPANTS: Data come from the National Patient Care Database and Pharmacy Benefits Management Database for primary care patients from 1999 to 2011, from nine Veteran Integrated Service Networks.

MEASURES: We developed four population-based quality metrics for depression care that incorporate a 6month look back and 1-year follow-up: detection of a new episode of depression, 84 and 180 day follow-up, and minimum appropriate treatment 1-year post detection. Expert panel techniques were used to evaluate the measure development methodology and results. Key challenges to creating valid longitudinal measures are discussed.

KEY RESULTS: Over the decade, the rates for detection of new episodes of depression remained stable at 7-8\%. Follow-up at 84 and 180 days were $37 \%$ and $45 \%$ in 2000 and increased to $56 \%$ and $63 \%$ by 2010 . Minimum appropriate treatment remained relatively stable over the decade (82-84 \%).

CONCLUSIONS: The development of valid longitudinal, population-based quality measures for depression care is a complex process with numerous challenges. If the full spectrum of care from detection to follow-up and treatment is not captured, performance measures could actually mask the clinical areas in need of quality improvement efforts.

Published online March 7, 2016
KEY WORDS: performance measurement; depression; Veterans; measurement; quality assessment.

J Gen Intern Med 31(Suppl 1):S36-45

DOI: $10.1007 / \mathrm{s} 11606-015-3563-4$

(c) Society of General Internal Medicine 2015

\section{INTRODUCTION}

Depression is the leading cause of reversible disability among primary care patients, the major precursor to suicide, contributes to the development and severity of chronic illnesses such as heart disease and diabetes, and increases cost among affected patients with comorbid diseases. ${ }^{1-5}$ Veterans experience a high burden of depression, with approximately $12 \%$ of Veterans attending the Veterans Health Administration (VA) primary care practices having symptoms of major depression. ${ }^{6}$

The VA has invested substantially in evidence-based mental health care. A major initiative focused on implementing collaborative care management (CCM) for depression care in primary care was incorporated into the VA Uniform Mental Health Services Handbook (2007) ${ }^{7}$ mandating primary care/ mental health integration nationally. It specifically recognized collocated mental health specialists in primary care and CCM as requirements for all primary care sites with at least 5000 patients. CCM clinical goals are to ensure that primary care patients identified with depression are assessed, treated, followed frequently, and receive self-management support as indicated in national depression guidelines. ${ }^{8}$ Management of depression in primary care using CCM for improving treatment can significantly reduce depressive symptoms, ${ }^{9-11}$ lower risk of depression reoccurrence, ${ }^{12}$ prevent prolonged disability, ${ }^{13}$ job loss, ${ }^{14-16}$ negative life events, ${ }^{17}$ and reduce suicide rates. $^{18}$

Yet achieving these favorable outcomes in routine clinical practice is challenging, and a barrier has been the lack of valid, reliable measures to evaluate improvement efforts. ${ }^{19-21}$ For many conditions, performance metrics have been a major force for improved care. ${ }^{22}$ VA has required yearly screening 
for depression over the last decade and has used screening rates to monitor performance (as with HbA1c). In 2008, VA introduced additional national performance measures to assess depression follow-up, only to withdraw them 2 years later. These additional measures encountered substantial resistance from primary care practice sites due to difficulties in interpreting site-level results - the level at which CCM improvements must be implemented. Therefore, our goal was to develop and validate prototype electronic measures suitable for evaluating VA's CCM initiative from 2000 to 2010 at the primary care practice site level. To this end, we developed site-level measures that used only electronic data, followed patients longitudinally through detection and treatment, and reflected care for the full primary care population at a given primary care location. ${ }^{23,24}$ We based the measures on depression guidelines and on those used in prior CCM evaluations. ${ }^{14}$ We then reviewed the measures and our development methodology with an expert panel of VA and non-VA experts.

Measure development was guided by the Donabedian model of quality that links healthcare structure, process and outcomes. ${ }^{25}$ Prior work has shown a link with depression process measures derived from administrative data and hospitalization outcomes. ${ }^{26}$ In terms of reducing or eliminating depression symptoms, though, the lack of timed and electronically documented symptom assessment data means that neither administrative review nor electronic measures can measure depression symptom outcomes. As done in prior studies, ${ }^{27,} 28$ our work focuses on actionable guideline-based depression care processes ${ }^{29}$ guidelines in turn reflect evidence linking these processes to outcomes. ${ }^{30}$ The objectives are to 1) describe the development process and challenges to developing prototype measures that capture the longitudinal course of clinical care from detection through treatment; 2) assess measure validity and limitations through an expert panel; and 3) examine the proportion of Veterans in primary care that met those depression quality measures (detection, follow-up and minimal appropriate treatment) at the VA from 2000 to 2010.

\section{METHODS}

\section{Design}

We used a systematic approach to identify a population, determine inclusion and exclusion criteria for the cohorts, develop quality measures, and map how each patient was accounted for in each measure. Per the domains identified by Hermann, ${ }^{31}$ we expected our measures to be meaningful, feasible, and actionable for quality improvement. For meaningfulness, we relied on literature, guidelines and an expert panel. For feasibility, we assessed whether we could program measures that accurately accounted for the full target population at each branch node of our measurement algorithm using counting trees. For actionability, we used benchmarks from the literature, interpretability by our expert panel, and applicability to assessing CCM.

\section{Expert Panel}

In March 2015, we convened a 1-day modified Delphi expert panel $^{17,32}$ to review our development methods and the results of applying our measures. Panelists included VA and non-VA experts in quality and performance measurement, depression, primary care/mental health integration, and program evaluation. Prior to the meeting, panelists received a detailed report on measure development and results. They completed an online survey (available from the authors) to evaluate sampling decisions and definitions, and on the importance and feasibility of electronic depression quality measurement. Survey results were presented to the panelists at the meeting. Summary notes were taken on a flip chart, and panelists were asked to vote on the summaries in real time. Two investigators took detailed notes.

\section{Data}

We used existing VA electronic medical record data from the National Patient Care Database and prescription data from Pharmacy Benefits Management Database to pull cohorts of all primary care patients during the federal fiscal years (FY) 2000-2010 from nine Veteran Integrated Service Networks (VISNs). Our larger project focused on the VA implementation of CCM over the decade, so we included four VISNs that implemented CCM early and five additional VISNs from across the United States to represent diverse levels of involvement with mental health primary care models and geographical diversity. The Greater Los Angeles Human Subjects Institutional Review Board approved this study.

\section{Identification of the Population}

Identifying the appropriate patient population on which to apply quality measures is a critical component of measure development. In our case, this challenge included identifying patients seen in primary care, determining the index visit, establishing continuity of care, and validating an algorithm to exclude patients with recent prior diagnosis or depression treatment. Issues related to timing of visits, timing of exclusion criteria, and cut-points for prescription medications and refills had to be considered. Figure 1 illustrates the development process.

Primary Care Cohort and Index Visit. The cohorts of patients for each measure included all patients seen in primary care for each FY, 2000-2010. The baseline visit (defined "index visit") was a patient's first primary care visit after the start of a given FY based on primary care visit encounter identifiers (for the VA: "clinic stop codes").

Continuously Seen Cohort and Home Site. The patient must have been seen at their primary care site at least once within the 12 months prior to the index visit $\left(\mathrm{T}_{0}-12\right)$ and again in the 12 months after the index visit $\left(\mathrm{T}_{0}+12\right)$. This definition of 


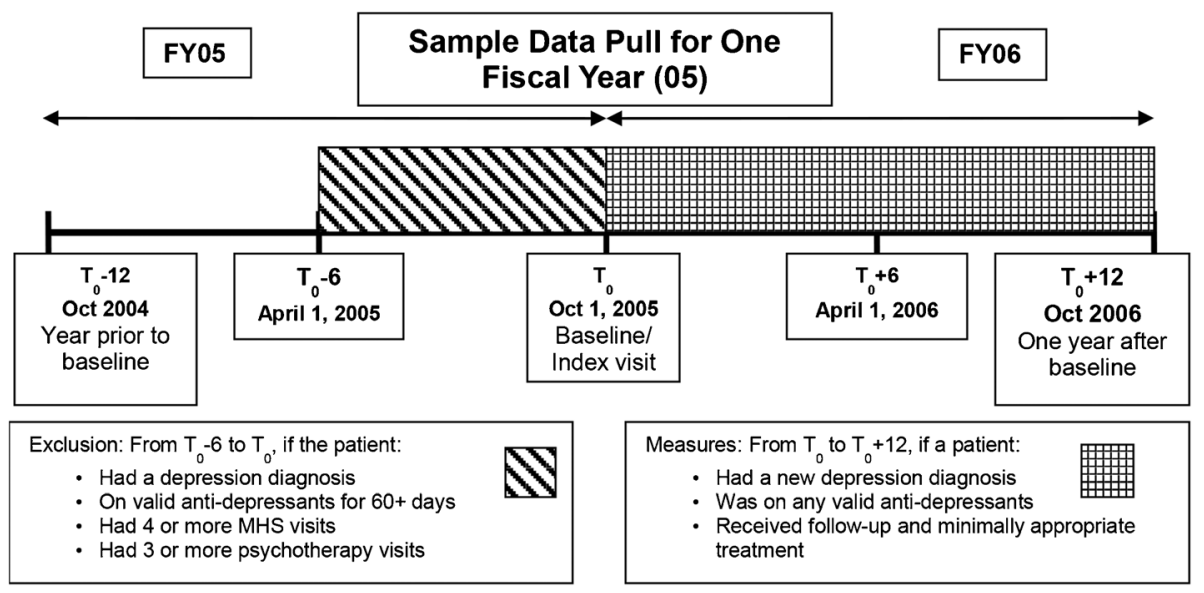

Figure 1. Identification of a new episode of depression for patients without depression diagnosis or minimal treatment in 6 months prior to index visit: example of how a patient was identified in federal fiscal year (FY) 2005.

"continuously seen" allows for sufficient time for follow-up and helps avoid truncated data. To assign each patient a home site, we used an algorithm similar to those used in a variety of primary care studies. $^{33,34}$ The algorithm stipulates that a patient's "home site" is the site with the most primary care visits for that patient over the 2-year period. For ties, we used the site with the most recent visit, or when sites differed in complexity of services (e.g., a large medical center versus a smaller community based outpatient clinic), we chose the smaller, less complex site.

\section{Exclusion for Depression Diagnosis or Treatment in Prior 6} Months. To limit the measures to patients with a new episode of depression, we excluded patients with a depression diagnosis (based on ICD-9 codes for depression, shown in Appendix 1 available online), or who had received minimally appropriate treatment in the 6 months prior to the index visit $\left(\mathrm{T}_{0}-6\right)$. Minimally appropriate treatment was defined as $\geq 60$ days of depression prescriptions (list of antidepressant drugs shown in Appendix 2 available online), $\geq 4$ mental health visits (VA clinic stop codes shown in Appendix 3 available online), or $\geq 3$ psychotherapy visits (Current Procedural Terminology (CPT) codes shown in Appendix 4 available online).

\section{Measures}

Based on depression care literature, prior quality measures from the VA and the National Committee for Quality Assurance (NCQA), and depression guidelines, we developed four population-based quality metrics for depression care to follow patients electronically over time (see measures in Table 1). Each reported measure uses as a denominator only the subset of patients to whom the measure is applicable. For example, detection is the proportion of patients who had a newly detected episode of depression (numerator) over the eligible population of primary care patients without recent depression diagnosis or minimally appropriate treatment (denominator). The proportion of patients with follow-up and minimally appropriate treatment (numerators) uses the denominator of all patients with a newly detected episode of depression. The ICD-9 codes, medications, stop codes and CPT codes that we used are shown in Appendices 1, 2, 3 and 4 available online.

Measure 1: Detection of new episode of depression: Detection of a new episode of depression was defined as a clinic visit with an ICD-9 code for depression or any antidepressant prescription in the 12 month period after the index visit.

Measures 2 \& 3: Follow-up of patient with new episode of depression: Following NCQA measures, we evaluated follow-up for a new depression diagnosis within 84 days and 180 days. Appropriate follow-up was defined as $\geq 3 \mathrm{MH}$ visits, or $\geq 3$ psychotherapy visits, or $\geq 3$ primary care visits with a depression ICD-9 diagnosis within 84 or 180 days of the newly detected episode.

Measure 4: Minimally appropriate treatment for patients with a new episode of depression: Minimally appropriate treatment was defined as having $\geq 60$ days of antidepressants, or $\geq 4$ MHS visits, or $\geq 3$ psychotherapy visits within 12 months post detection. For prescriptions, we used the cut point of $\geq 60$ days of prescription medications to indicate at least one medication refill. We excluded prescriptions with non-depression indication/keywords written on the dosing instructions, and prescriptions with a subtherapeutic dose (see Appendix 2 available online for details).

\section{Accounting for All Patients in Each Measure}

We used a counting hierarchy (counting trees) to document the number of patients retained and excluded at all steps of measure construction. The counting hierarchy ensures that every patient in the original primary care population cohort is accounted for across each branch in the logic, such that at each node, the sum of patients meeting and not meeting each criterion equals the full initial population. 
Table 1. Quality of Depression Care Measures

\begin{tabular}{|c|c|c|}
\hline Constructed measure & Description of measure & Time frame \\
\hline Detection of a new episode of depression & $\begin{array}{l}\text { Number of patients detected with a new episode of depression (numerator) } \\
\text { over the number of primary care patients who in the } 6 \text { months prior to the } \\
\text { index visit were undiagnosed and untreated for depression (denominator) }\end{array}$ & $\begin{array}{l}12 \text { months from } \\
\text { index visit }\end{array}$ \\
\hline $\begin{array}{l}\text { Follow-up of a patient with a new episode of the } \\
\text { depression detected within } 84 \text { days of detection }\end{array}$ & $\begin{array}{l}\text { Number of patients who received follow-up with three or more MHS visits, } \\
\text { three or more psychotherapy visits, or three or more primary care visits } \\
\text { with a depression ICD-9 diagnosis within } 84 \text { days of detection of new } \\
\text { depression (numerator) over the number of patients with a new episode of } \\
\text { depression detected (denominator) }\end{array}$ & $\begin{array}{l}84 \text { days from } \\
\text { detection }\end{array}$ \\
\hline $\begin{array}{l}\text { Follow-up of a patient with a new episode of the } \\
\text { depression detected within } 180 \text { days of detection }\end{array}$ & $\begin{array}{l}\text { Number of patients who received follow-up with three or more MHS visits, } \\
\text { three or more psychotherapy visits, or three or more primary care visits } \\
\text { with a depression ICD-9 diagnosis within } 180 \text { days of detection of new } \\
\text { depression (numerator) over the number of patients with a new episode of } \\
\text { depression detected (denominator) }\end{array}$ & $\begin{array}{l}180 \text { days from } \\
\text { detection }\end{array}$ \\
\hline Minimally appropriate treatment & $\begin{array}{l}\text { Number of patients who complete } 60 \text { or more days of antidepressants, four } \\
\text { or more MHS visits, or three or more psychotherapy visits within } \\
12 \text { months of the visit where the new episode of depression was detected } \\
\text { (numerator) over the number of patients with a new episode of depression } \\
\text { detected (denominator) }\end{array}$ & $\begin{array}{l}12 \text { months from } \\
\text { detection }\end{array}$ \\
\hline
\end{tabular}

Depression diagnosis based on ICD-9 codes are shown in Appendix 1, Prescriptions used as antidepressants are shown in Appendix 2; Mental health visits based on 500 level clinic stop codes are shown in Appendix 3; Psychotherapy visits based on CPT-codes are shown in Appendix 4. Appendices 1, 2, 3 and 4 are available online

\section{RESULTS}

Overview. Measure development focused on using counting trees to continuously verify application of measures to the primary care population, and measure application focused on using the measures to assess depression care from FY2000 to FY2010 in nine VISNs. The expert panel reviewed and critiqued measure development and application.

Counting Trees. Counting trees show that programming accurately accounted for all patients in the population at every branch node. Figure 2 is the counting tree for minimally appropriate treatment for FY2005. The tree begins on the far left with the cohort of all patients who had an index visit in primary care during FY2005 from the nine VISNs $\quad(n=2,011,849)$. The next branch shows which patients were continuously seen in their primary care site over the 2-year period $(n=1,574,532)$. Twenty-two percent $(n=437,317)$ had not been seen continuously and therefore were not eligible for the measure. The next branches exclude patients who had a prior diagnosis of depression $(n=53,221)$ or had completed minimal treatment for depression in the prior 6 months $(n=201,814)$. Of the remaining $1,319,497$ patients, 94,130 patients had a new episode of depression detected in FY2005 (7 \% of the eligible population). Among those patients with a new episode of depression detected, $82 \%(n=77,533)$ completed minimally appropriate treatment within 12 months of detection.

Counting trees assessed meaningfulness (through face validity of the branches), but can also be used for quality improvement (to assess what happens to those not meeting the measure). For example, in FY2005, the bottom branch identified that $22 \%$ of the patients had not been continuously seen twice in 2 years, 16,909 had an ICD-9 diagnosis for depression in
6 months prior to the index visit, and 13,008 patients had not received minimally appropriate treatment in the prior 6 months. Among the 13,008 patients, $86 \%(n=11,167)$ had an additional episode of depression detected, and $12 \%$ did not receive minimally appropriate treatment within 12 months of detection.

Measures Over Time in Nine VISNs. Over the decade, there was a substantial increase in the number of patients seen in primary care in the nine VISNs, from 1.19 million in FY2000 to over 2.26 million in FY2010 (Fig. 3). The cohort without a depression diagnosis or active treatment in the prior 6 months ranged from 790,000 to 1.35 million and the rates for detection of new episodes of depression remained stable at $7-8 \%$ over the years (not shown). Follow-up at 84 and 180 days was $37 \%$ and $45 \%$ in FY2000, and increased to $56 \%$ and $63 \%$ by FY2010 (Fig. 4). Minimally appropriate treatment remained relatively stable at $84 \%$ in FY2000, dropped to $82 \%$ in FY2005, and was $83 \%$ in FY2010.

\section{Expert Panel Evaluation of the Measures as Developed and} Applied. The expert panel included 14 panelists, four of whom were also on the project team. Analysis of the pre-meeting survey ( $86 \%$ response rate) data showed a high level of agreement on the appropriateness of most measurement development and cohort construction methods, including the decision to use antidepressants prescribed in primary care as a signal for depression detection, even without an accompanying ICD-9 diagnosis. Panelists also validated the cohort definitions and counting tree based methods. For the definition of new depression, panelists suggested the name "new episode of depression" to indicate that the patient may have been previously diagnosed, but had not been diagnosed or treated for the previous 6 months. For the treatment measure, panelists judged the threshold for treatment completion we used, although based on prior 


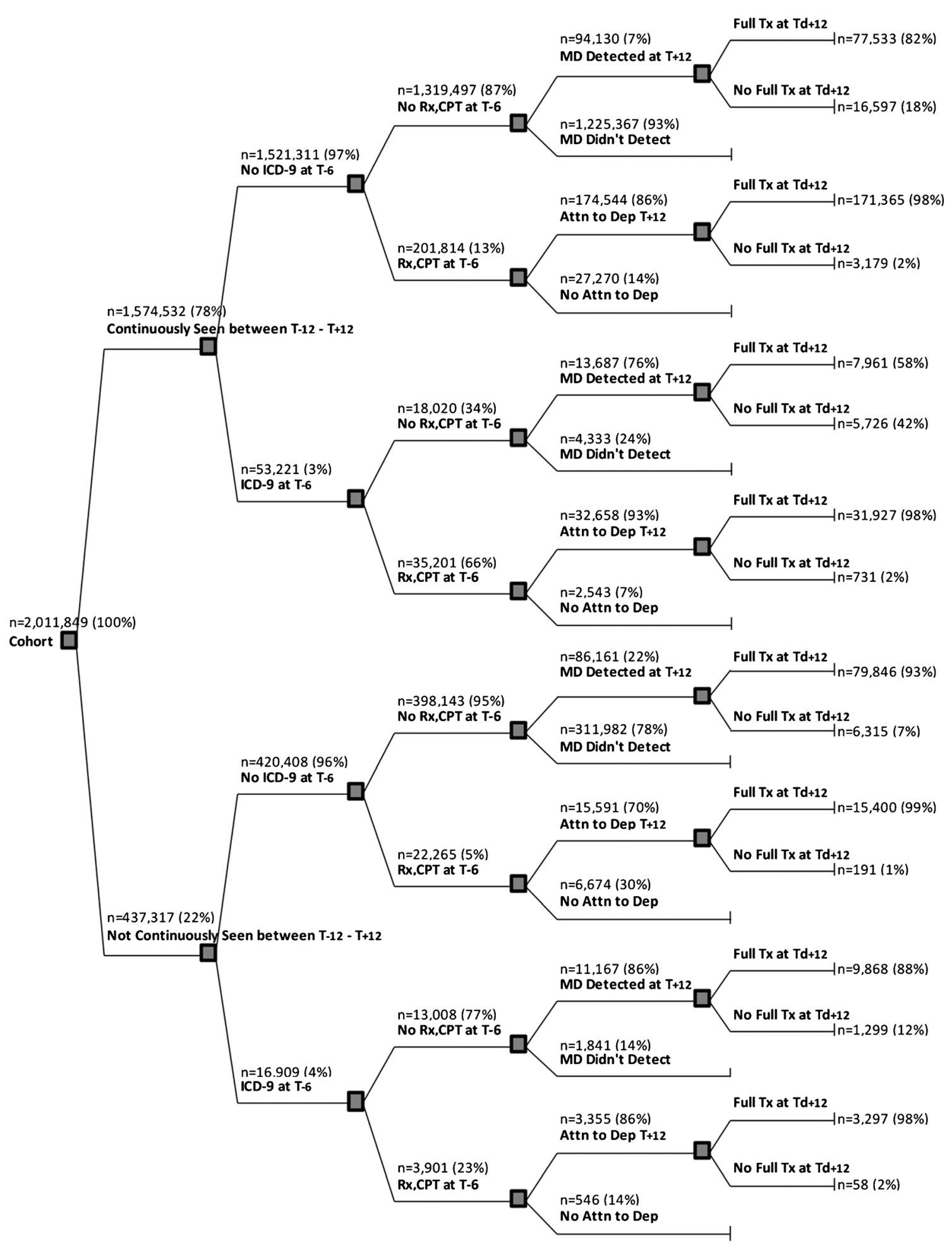

Figure 2. Counting tree for completion of minimally appropriate treatment 12 months after detection of a new episode of depression in federal fiscal year 2005. Abbreviations in figure: No ICD-9 at $T_{-6}$ (vs. ICD-9 at $T_{-6}$ ) = Exclude patients who had a diagnosis of depression in the 6 months prior to index visit. No Rx, CPT at $T_{-6}\left(v s\right.$. Rx, CPT at $\left.T_{-6}\right)=$ Exclude patients who completed a minimal course of treatment for depression in the prior 6 months. Attn to Dep (vs. No Attn to Dep) = There was attention (treatment) to depression found. MD Detected (vs. MD

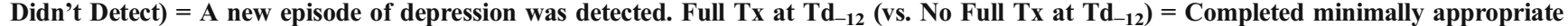
treatment within 12 months of detection of a new episode of depression.

studies, ${ }^{14}$ to be too low relative to optimal treatment, especially given the severity and complexity of depression among Veterans. Panelists suggested terming the measure "minimally appropriate treatment." They discussed future potential modifications, including requiring 90 days of antidepressants (expanded from the 60 day requirement) and/or 90 days of continuous antidepressants. They also discussed restricting the 60 days of medications to be within 90 days of detection (as 


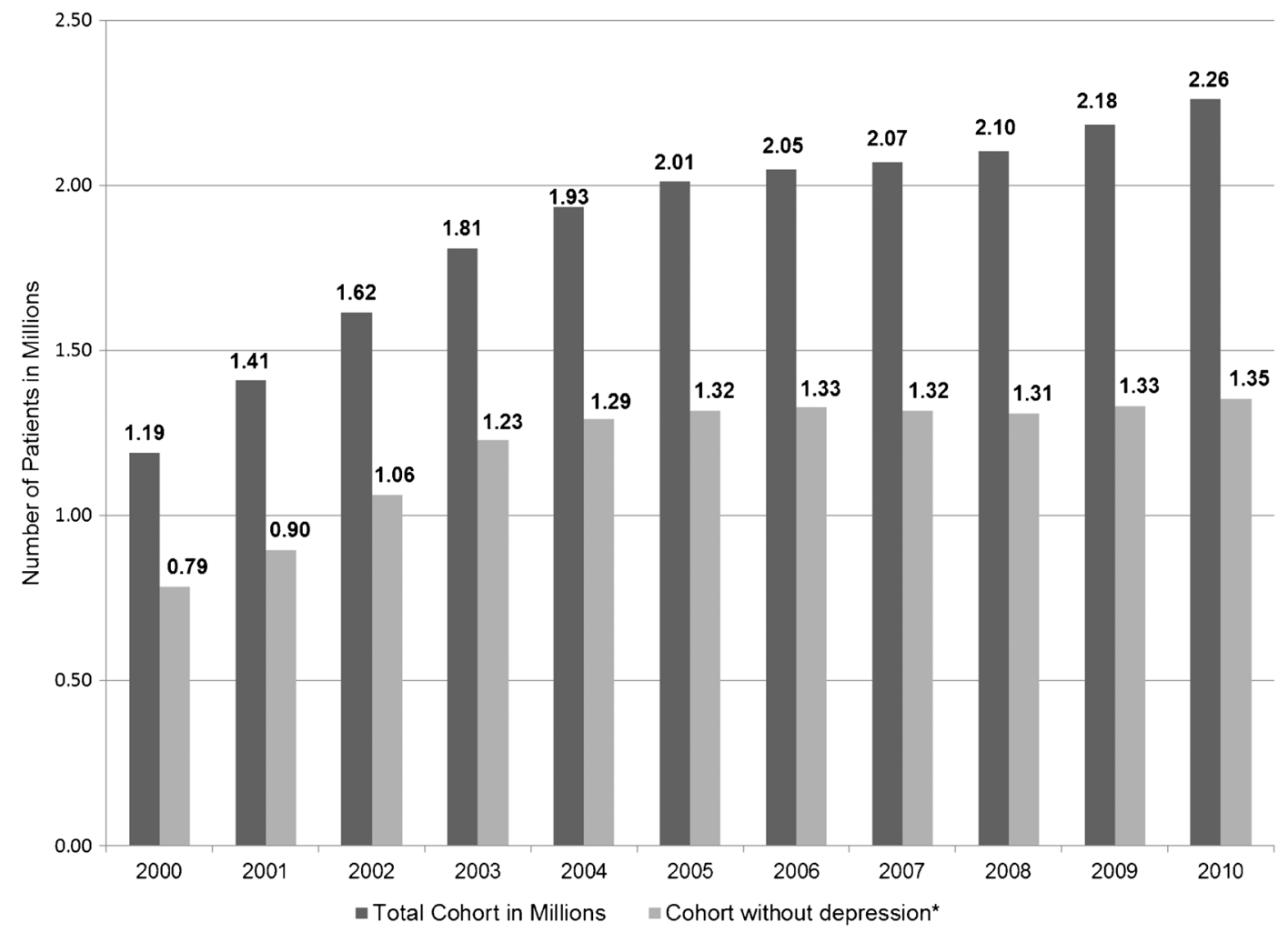

Figure 3 Cohorts of VA primary care patients from the nine Veteran integrated service networks in federal fiscal years $2000-2010$ (in millions). *Patients without a depression diagnosis or actively treated in 6 months prior to index visit.

opposed to 12 months). To address continuity of treatment, panelists suggested that in the future, measures should require mental health visits (or psychotherapy visits) to be with the same provider. Panelists also endorsed the future goal of similar depression care measures for evaluating the population of patients screening positive for depression in primary care.

\section{DISCUSSION}

The VA saw rapid growth in primary care patients from FY2000 to FY2010, increasing by over one million patients. Despite rapid growth, our measures indicate that the detection of new episodes of depression (8\%) and minimally appropriate treatment rates $(84 \%)$ remained stable, suggesting VA was able to maintain a standard of care while treating significantly more patients each year.

While our measure of treatment completion mirrors standards used in prior clinical quality improvement trials, ${ }^{14,27}$ our expert panel judged that future iterations of this measure need to incorporate a higher minimal treatment threshold. This is feasible without changes to the basic measure approach we used. Future efforts to develop measures to identify excellent care should consider, however, the potential tradeoffs if electronic measures become too specific. Tradeoffs can include greater potential for error, lower measure reliability, and

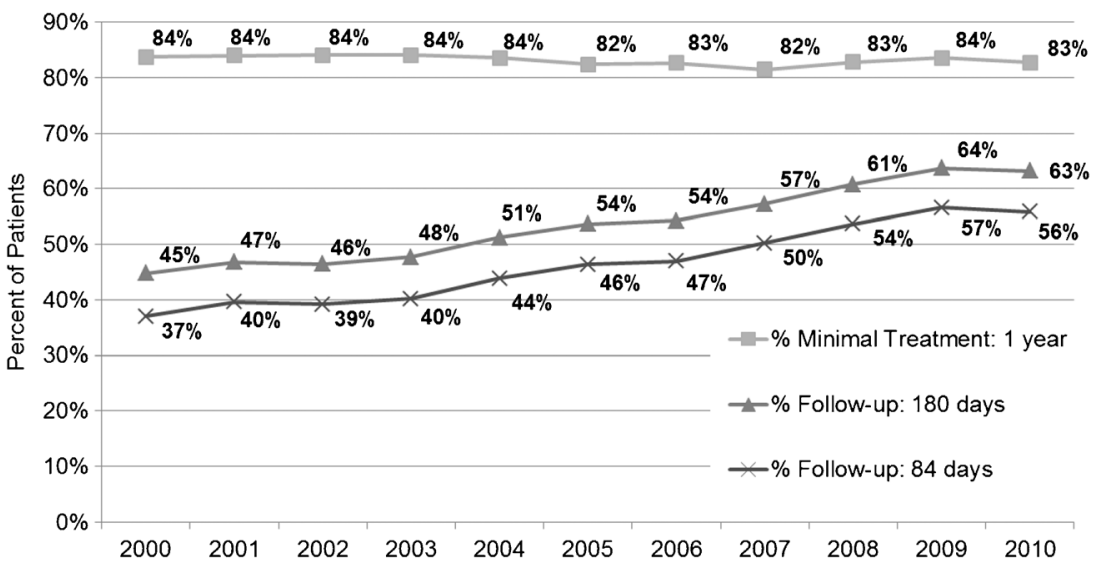

Figure 4. Among patients with a new episode of depression detected, percent of patients with follow-up and minimal treatment completion (FY2000-FY2010). 
greater likelihood of using censored data that does not reflect the care for the full relevant population of interest. Furthermore, measures focused on enhancing access to basic care (e.g., performance of $\mathrm{HbA} 1 \mathrm{c}$ or following up detected depression) often have large impacts on patient outcomes. Low threshold measures often identify patients receiving severely inadequate care and thus in most need of intervention.

Follow-up rates increased for both 84-day and 180-day follow-up (18-19\% increase), indicating improvements in timely treatment initiation and follow-up; yet showed lower adherence than did our treatment measure. Substantial evidence indicates that non-face-to-face modalities can effectively substitute for frequent visits but administrative codes for these were not available during our study period. Reliable coding of telephone, telehealth, and secure messaging encounters is now available in the VA, and future measures using our development methodology can feasibly incorporate these follow-up modalities.

The measures development methodology, including patient assignment, identifying new depression episodes, and evaluating treatment over time proved feasible and led to measures that were stable over time and across multiple primary care sites and regions. The counting trees verify and validate the algorithms underlying the measures and systematically reference the full primary care population to avoid errors due to loss of subjects. Additionally, counting trees can be used to make measures more actionable to local sites. The strict attention to the branching algorithm, the multiple data sources, and the timing of measures around an index visit creates programming challenges, yet is critical.

Using administrative data for measure development has limitations. The measures we developed advance electronic measurement by moving beyond detection based purely on ICD-9 codes to consider new antidepressant use. ${ }^{20}$ Based on ICD-9 codes alone, the detection rate was $1 \%$, but adding use of antidepressants for depression resulted in detection of an additional $6-7 \%$ of primary care patients. However, the $7-8 \%$ detection rate was still considerably lower than published detection rates based on survey-based depression screening. ${ }^{6} \mathrm{We}$ preliminarily tested incorporating a PHQ-2 based detection approach into our measures (unpublished) using FY2010 data and found it to be feasible. In this approach, screening positive is used to identify the applicable population (denominator) and the cohort is then linked to the quality measures. However, because our project required stable measures spanning FY2000-FY2010, and standardized national data on screening (e.g., PHQ-2 and PHQ-9) was not available until FY2008, we could not incorporate these screening/symptom measures into the measurement algorithms. Finally, we developed an antidepressant algorithm to exclude prescriptions for non-depression indications; however, antidepressants used for other conditions (sleep, pain, migraines, etc.) may not have been entirely excluded. Future attention to promoting coding that indicates non-depression-related antidepressant use could improve measure accuracy.

We developed electronic population-based longitudinal depression quality measures that met reasonable standards as meaningful, feasible and actionable ${ }^{31}$ for assessing VA depression care over a decade. Our current data shows that VA improved depression follow-up between FY2000 and FY2010, and that treatment rates compared favorably with non-VA benchmarks. Looking forward, our measure development methodology can feasibly be adapted to incorporate more stringent definitions of treatment, depression symptom screening data, and future enhancements in care. The methodology and techniques we used to address measurement challenges provide a basis for future performance measure development, especially for other chronic conditions where longitudinal care must be captured.

Acknowledegments: Funding for this research was supported by a grant from VA Health Services Research \& Development (Project \#IIR 11-326; PI: Farmer). We would like to acknowledge the expert panelists for their contribution as well as Britney Chow, MPH and Ismelda Canelo, MPA for administrative support.

The views expressed in the manuscript are solely those of the authors, and do not necessarily represent the views of the U.S. Department of Veterans Affairs or the United States government.

Corresponding Author: Melissa M. Farmer, PhD; VA HSR\&D Center for the Study of Healthcare Innovation, Implementation \& Policy, VA Greater Los Angeles Healthcare System, 16111 Plummer Street (152), Sepulveda, CA 91343, USA (e-mail: Melissa.Farmer@va.gov).

\section{Compliance with Ethical Standards:}

Conflict of Interest: The authors declare that they do not have a conflict of interest.

\section{REFERENCES}

1. Katon WJ, Lin EH, Von Korff M, Ciechanowski P, Ludman EJ, Young B, et al. Collaborative care for patients with depression and chronic illnesses. N Engl J Med. 2010;363(27):2611-20.

2. Wells KB, Burnam MA, Rogers W, Hays R, Camp P. The course of depression in adult outpatients. Results from the medical outcomes study. Arch Gen Psychiatry. 1992;49(10):788-94.

3. Wells KB, Sherbourne CD. Functioning and utility for current health of patients with depression or chronic medical conditions in managed, primary care practices. Arch Gen Psychiatry. 1999;56(10):897-904.

4. Murray CJ, Lopez AD. The global burden of disease: a comprehensive assessment of mortality and disability from disease, injuries, and risk factors in 1990 and projected to 2020. Boston, MA: The Harvard School of Public Health on behalf of the World Health Organization and the World Bank; 1996.

5. Kessler RC, Chiu WT, Demler O, Merikangas KR, Walters EE. Prevalence, severity, and comorbidity of 12-month DSM-IV disorders in the national comorbidity survey replication. Arch Gen Psychiatry. 2005;62(6):617-27.

6. Yano EM, Chaney EF, Campbell DG, Klap R, Simon BF, Bonner LM, et al. Yield of practice-based depression screening in VA primary care settings. J Gen Intern Med. 2012;27(3):331-8.

7. Uniform Mental Health Services; http://vaww1.va.gov/vhapublications/ ViewPublication.asp?pub_ID=1762. Accessed November 18, 2015.

8. Panel DG. Depression in primary care, Vol II: treatment of major depression: clinical practice guide-line 5. In: AfHCPa, ed. Research. AHCPR Publication 93-0551: Rockville, MD; 1993.

9. Gilbody S, Bower P, Fletcher J, Richards D, Sutton AJ. Collaborative care for depression: a cumulative meta-analysis and review of longer-term outcomes. Arch Intern Med. 2006;166(21):2314-21.

10. Coventry PA, Hudson JL, Kontopantelis E, Archer J, Richards DA, Gilbody S, et al. Characteristics of effective collaborative care for treatment of depression: a systematic review and meta-regression of 74 randomised controlled trials. PLoS ONE. 2014;9(9):e108114.

11. Archer J, Bower P, Gilbody S, Lovell K, Richards D, Gask L, et al. Collaborative care for depression and anxiety problems. Cochrane Database Syst Rev. 2012;10:CD006525. 
12. Katon W, Unutzer J, Wells $\mathbf{K}$, Jones L. Collaborative depression care: history, evolution and ways to enhance dissemination and sustainability. Gen Hosp Psychiatry. 2010;32(5):456-64.

13. Sherbourne CD, Edelen MO, Zhou A, Bird C, Duan N, Wells KB. How a therapy-based quality improvement intervention for depression affected life events and psychological well-being over time: a 9-year longitudinal analysis. Med Care. 2008;46(1):78-84.

14. Wells KB, Sherbourne C, Schoenbaum M, Duan N, Meredith L, Unutzer J, et al. Impact of disseminating quality improvement programs for depression in managed primary care: a randomized controlled trial. JAMA. 2000;283(2):212-20.

15. Wells K, Sherbourne C, Schoenbaum M, Ettner S, Duan N, Miranda J, et al. Five-year impact of quality improvement for depression: results of a group-level randomized controlled trial. Arch Gen Psychiatry. 2004;61(4):378-86.

16. Smith JL, Rost KM, Nutting PA, Libby AM, Elliott CE, Pyne JM. Impact of primary care depression intervention on employment and workplace conflict outcomes: is value added? J Ment Health Policy Econ. 2002;5(1):43-9.

17. Rubenstein LV, Chaney EF, Ober S, Felker B, Sherman SE, Lanto A, et al. Using evidence-based quality improvement methods for translating depression collaborative care research into practice. Fam Syst Health. 2010;28(2):91-113.

18. Unutzer J, Tang L, Oishi S, Katon W, Williams JW Jr, Hunkeler E, et al. Reducing suicidal ideation in depressed older primary care patients. J Am Geriatr Soc. 2006;54(10):1550-6.

19. Essock SM, Olfson M, Hogan MF. Current practices for measuring mental health outcomes in the USA: international overview of routine outcome measures in mental health. Int Rev Psychiatry. 2015;27(4):296-305.

20. Solberg LI, Engebretson KI, Sperl-Hillen JM, Hroscikoski MC, O'Connor PJ. Are claims data accurate enough to identify patients for performance measures or quality improvement? The case of diabetes, heart disease, and depression. Am J Med Qual. 2006;21(4):238-45.

21. Hermann RC, Provost S. Best practices: interpreting measurement data for quality improvement: standards, means, norms, and benchmarks. Psychiatr Serv. 2003;54(5):655-7.

22. Asch SM, McGlynn EA, Hogan MM, Hayward RA, Shekelle P, Rubenstein L, et al. Comparison of quality of care for patients in the
Veterans Health Administration and patients in a national sample. Ann Intern Med. 2004;141(12):938-45.

23. Bynum JP, Bernal-Delgado E, Gottlieb D, Fisher E. Assigning ambulatory patients and their physicians to hospitals: a method for obtaining population-based provider performance measurements. Health Serv Res. 2007;42(1 Pt 1):45-62.

24. Ross JS, Siu AL. The importance of population-based performance measures. Health Serv Res. 2007;42(1 Pt 1): 1-6.

25. Donabedian A. The quality of care. How can it be assessed? JAMA 1988;260(12): 1743-8.

26. Charbonneau A, Rosen AK, Owen RR, Spiro A 3rd, Ash AS, Miller DR, et al. Monitoring depression care: in search of an accurate quality indicator. Med Care. 2004;42(6):522-31.

27. Hepner KA, Rowe M, Rost K, Hickey SC, Sherbourne CD, Ford DE, et al. The effect of adherence to practice guidelines on depression outcomes. Ann Intern Med. 2007;147(5):320-9.

28. Kahn KL, Tisnado DM, Adams JL, Liu H, Chen WP, Hu FA, et al. Does ambulatory process of care predict health-related quality of life outcomes for patients with chronic disease? Health Serv Res. 2007;42(1 Pt 1):63-83.

29. Kerr EA, Krein SL, Vijan S, Hofer TP, Hayward RA. Avoiding pitfalls in chronic disease quality measurement: a case for the next generation of technical quality measures. Am J Manag Care. 2001;7(11):1033-43.

30. Major Depression Working Group. VA/DoD clinical practice guideline for management of major depressive disorder. In: Do D, ed. Washington DC: Department of Veterans Affairs; 2009.

31. Hermann RC, Palmer RH. Common ground: a framework for selecting core quality measures for mental health and substance abuse care. Psychiatr Serv. 2002;53(3):281-7.

32. Rubenstein LV, Fink A, Yano EM, Simon B, Chernof B, Robbins AS. Increasing the impact of quality improvement on health: an expert panel method for setting institutional priorities. Jt Comm J Qual Improv. 1995;21(8):420-32.

33. Farmer M. Identifying successful approaches to smoking cessation treatment for veterans, final report for HSR\&D project IIR 04-380. Sepulveda, CA: VHA HSR\&D; 2010.

34. Yano E. VA's quality transformation: lessons for evidence-based management, final report for HSR\&D project IIR 06-087. Sepulveda, CA: VHA HSR\&D; 2010.

\section{APPENDICES}

Table 2. ICD-9 Codes Used for Depression Diagnosis

\begin{tabular}{|c|c|c|c|}
\hline \multirow[t]{2}{*}{ ICD-9 } & \multirow[t]{2}{*}{ Description } & \multicolumn{2}{|l|}{ Used for: } \\
\hline & & *Exclude & Follow-up \\
\hline 293.83 & Organic affective syndrome & $\mathrm{X}$ & $\mathrm{X}$ \\
\hline $296.2 \mathrm{x}$ & Major depressive disorder single episode & $\mathrm{X}$ & $\mathrm{X}$ \\
\hline 296.21 & Major depressive affective disorder single episode mild degree & $\mathrm{X}$ & $\mathrm{X}$ \\
\hline 296.22 & Major depressive affective disorder single episode moderate degree & $\mathrm{X}$ & $\mathrm{X}$ \\
\hline 296.23 & Major depressive affective disorder single episode severe degree without psychotic behavior & $\mathrm{X}$ & $\mathrm{X}$ \\
\hline 296.24 & Major depressive affective disorder single episode severe degree specified with psychotic behavior & $\mathrm{X}$ & $\mathrm{X}$ \\
\hline 296.25 & Major depressive affective disorder single episode in partial or unspecified remission & $\mathrm{X}$ & $\mathrm{X}$ \\
\hline 296.26 & Major depressive affective disorder single episode in full remission & $\mathrm{X}$ & $\mathrm{X}$ \\
\hline $296.3 \mathrm{x}$ & Major depressive disorder recurrent episode unspecified degree & $\mathrm{X}$ & $\mathrm{X}$ \\
\hline 296.31 & Major depressive affective disorder recurrent episode mild degree & $\mathrm{X}$ & $\mathrm{X}$ \\
\hline 296.32 & Major depressive affective disorder recurrent episode moderate degree & $\mathrm{X}$ & $\mathrm{X}$ \\
\hline 296.33 & Major depressive affective disorder recurrent episode severe degree without psychotic behavior & $\mathrm{X}$ & $\mathrm{X}$ \\
\hline 296.34 & Major depressive affective disorder recurrent episode severe degree specified with psychotic behavior & $\mathrm{X}$ & $\mathrm{X}$ \\
\hline 296.35 & Major depressive affective disorder recurrent episode in partial or unspecified remission & $\mathrm{X}$ & $\mathrm{X}$ \\
\hline 296.36 & Major depressive affective disorder recurrent episode in full remission & $\mathrm{X}$ & $\mathrm{X}$ \\
\hline $296.5 \mathrm{x}$ & Bipolar I disorder, most recent episode (or current) depressed unspecified degree & $\mathrm{X}$ & $\mathrm{X}$ \\
\hline 296.51 & Bipolar I disorder, most recent episode (or current) depressed mild degree & $\mathrm{X}$ & $\mathrm{X}$ \\
\hline 296.52 & Bipolar I disorder, most recent episode (or current) depressed moderate degree & $\mathrm{X}$ & $\mathrm{X}$ \\
\hline 296.53 & Bipolar I disorder, most recent episode (or current) depressed severe degree without psychotic behavior & $\mathrm{X}$ & $\mathrm{X}$ \\
\hline 296.54 & Bipolar I disorder, most recent episode (or current) depressed severe degree specified with psychotic behavior & $\mathrm{X}$ & $\mathrm{X}$ \\
\hline 296.55 & Bipolar I disorder, most recent episode (or current) episode in partial or unspecified remission & $\mathrm{X}$ & $\mathrm{X}$ \\
\hline 296.56 & Bipolar I disorder, most recent episode (or current) depressed in remission & $\mathrm{X}$ & $\mathrm{X}$ \\
\hline 296.90 & Unspecified episodic mood disorder & & $\mathrm{X}$ \\
\hline 296.99 & Other specified affective psychoses & $\mathrm{X}$ & \\
\hline $298.0 \mathrm{x}$ & Depressive type psychosis & $\mathrm{X}$ & $\mathrm{X}$ \\
\hline $300.4 \mathrm{x}$ & Neurotic depression & $\mathrm{X}$ & $\mathrm{X}$ \\
\hline $309.0 \mathrm{x}$ & Brief depressive reaction as adjustment reaction & & $\mathrm{X}$ \\
\hline $309.1 \mathrm{x}$ & Prolonged depressive reaction as adjustment reaction & $\mathrm{X}$ & $\mathrm{X}$ \\
\hline $311 x$ & Depressive disorder not elsewhere classified (NEC) & $\mathrm{X}$ & $\mathrm{X}$ \\
\hline
\end{tabular}

*Exclusion for prior depression diagnosis 
Table 2. List of Antidepressant Drugs Used in Measures*

\begin{tabular}{ll}
\hline Amitriptyline & Nefazodone \\
Desipramine & Sertraline \\
Doxepin & Trazodone \\
Imipramine & Mirtazapine \\
Nortriptyline & Amoxapine \\
Citalopram & Clomipramine \\
Fluoxetine & Escitalopram \\
Paroxetine & Fluvoxamine \\
Phenelzine & Isocarboxazid \\
Tranylcypromine & Maprotiline \\
Venlafaxine & Protriptyline \\
Buproprion & Trimipramine \\
Duloxetine & Selegiline \\
\hline
\end{tabular}

*We excluded prescriptions with a non-depression indication/keywords written on the dosing instructions including 'neuropathy', 'pain', 'peripheral', 'sleep', 'insomnia', 'pruritis', 'itching', 'migraine', 'foot', 'head', 'ache', and 'itch'. We also excluded prescriptions with a smoking indication written in the dosing instructions ('smoke', 'tobacco', 'smoking'). We also excluded prescriptions with a low dose including if Amitriptyline HCL is less than 75 MG TAB, if Trazodone is less than $300 M G$, and if Mirtazapine is less than $45 M G$

Table 4. VA Clinic Stop Codes for Mental Health Visits

\begin{tabular}{ll}
\hline \hline Clinic stop & Description \\
code & \\
\hline 143 & Sleep study \\
165 & Bereavement counseling \\
292 & Observation psychiatry \\
501 & Homeless mentally ill outreach \\
502 & Mental health clinic - Individual \\
503 & Mental health residential care - Individual \\
504 & IPCC medical center visit \\
505 & Day treatment - Individual \\
506 & Day hospital - Individual \\
507 & Department of Housing \& Urban Development/VA \\
& Supportive Housing (HUD/VASH)-Group \\
508 & Health care for homeless Veterans/Homeless \\
& chronically mentally ill (HCHV/HCMI) - Group \\
509 & Psychiatry - Individual \\
510 & Psychology - Individual \\
511 & Grant and per diem - Individual \\
512 & Mental health consultation \\
513 & Substance use disorder - Individual \\
514 & Substance abuse - Home visit \\
515 & Compensated work therapy (CWT) / TR-HCMI \\
516 & Post traumatic stress disorder (PTSD) - Group \\
517 & Compensated work therapy (CWT) / Substance abuse \\
518 & Compensated work therapy (CWT) / TR-Substance \\
519 & abuse \\
520 & Substance use disorder / PTSD teams \\
521 & Long-term enhancement - Individual \\
522 & Long-term enhancement - Group \\
523 & Department of Housing and Urban Development \\
524 & (HUD) -VA Shared Housing (VASH) \\
525 & Opioid substitution \\
526 & Active duty sexual trauma \\
527 & Women's stress disorder treatment teams \\
528 & Telephone / Special psychiatry \\
529 & Mental health telephone \\
530 & Telephone homeless chronically mentally ill (HCMI) \\
531 & Health care for homeless Veterans (HCHV) / HCMI \\
532 & Telephone HUD/VASH \\
533 & Mental health primary care - Individual \\
534 & Psychosocial rehabilitation - Individual \\
535 & Mental health intervention biomedical \\
536 & \\
537 & \\
\hline & Cental health integrated care \\
&
\end{tabular}

Table 4. (continued)

\begin{tabular}{|c|c|}
\hline $\begin{array}{l}\text { Clinic stop } \\
\text { code }\end{array}$ & Description \\
\hline 538 & Psychological testing \\
\hline 539 & Mental health integration care - Group \\
\hline 540 & $\begin{array}{l}\text { Post-traumatic stress disorder (PTSD) clinical } \\
\text { team (PCT) Post-traumatic stress - Individual }\end{array}$ \\
\hline 541 & Post-traumatic stress disorder (PTSD) \\
\hline 542 & Telephone PTSD \\
\hline 543 & Telephone/alcohol dependence \\
\hline 544 & Telephone/drug dependence \\
\hline 545 & Telephone/substance use disorder \\
\hline 546 & $\begin{array}{l}\text { Telephone mental health intensive care } \\
\text { management (MHICM) }\end{array}$ \\
\hline 547 & Intensive substance abuse treatment - Group \\
\hline 548 & Intensive substance abuse disorder - Individual \\
\hline 550 & Mental health clinic - Group \\
\hline 551 & IPCC community clinic/day program visit \\
\hline 552 & Mental health intensive case management (MHICM) \\
\hline 553 & Day treatment - Group \\
\hline 554 & Day hospital - Group \\
\hline 555 & Drug dependence - Group \\
\hline 556 & Alcohol treatment - Group \\
\hline 557 & Psychiatry - MD Group \\
\hline 558 & Psychology - Group \\
\hline 559 & Psychosocial rehabilitation - Group \\
\hline 560 & Substance Abuse - Group \\
\hline 561 & PCT- Post traumatic stress - Group \\
\hline 562 & PTSD - Individual \\
\hline 563 & Mental health primary care team - Group \\
\hline 564 & Mental health team case management \\
\hline 566 & Mental health risk-factor reduction education group \\
\hline 567 & $\begin{array}{l}\text { Mental health intensive case management (MHICM) - } \\
\text { Group }\end{array}$ \\
\hline 568 & $\begin{array}{l}\text { Mental health compensated work therapy/Supported } \\
\text { employment (CWT/SE) face-to-face }\end{array}$ \\
\hline 569 & $\begin{array}{l}\text { Mental health CWT/Supported employment } \\
\text { (CWT/SE) non-face-to-face CBO non-count }\end{array}$ \\
\hline 570 & $\begin{array}{l}\text { MH CWT/Transitional work experience (TWE) } \\
\text { Non-face-to-face CBO Non-count }\end{array}$ \\
\hline 571 & $\begin{array}{l}\text { RVOEC (Returning Veterans outreach, education } \\
\text { and care) Individual }\end{array}$ \\
\hline 572 & $\begin{array}{l}\text { RVOEC (Returning Veterans outreach, education } \\
\text { and care) Group }\end{array}$ \\
\hline 573 & Mental health incentive therapy group face-to-face \\
\hline 574 & $\begin{array}{l}\text { MH CWT/Transitional work experience (TWE) } \\
\text { face-to-face }\end{array}$ \\
\hline 575 & Mental health vocational assistance - Group \\
\hline 576 & Psycho-geriatric clinic - Individual \\
\hline 577 & Psycho-geriatric clinic - Group \\
\hline 578 & Psycho-geriatric day program \\
\hline 579 & Telephone psycho-geriatrics \\
\hline 580 & PTSD day hospital \\
\hline 581 & PTSD day treatment \\
\hline 582 & $\begin{array}{l}\text { Psychosocial rehabilitation recovery center (PRRC) - } \\
\text { Individual }\end{array}$ \\
\hline 583 & $\begin{array}{l}\text { Psychosocial rehabilitation recovery center (PRRC) - } \\
\text { Group }\end{array}$ \\
\hline 584 & $\begin{array}{l}\text { Telephone psychosocial rehabilitation recover center } \\
\text { (PRRC) }\end{array}$ \\
\hline 588 & $\begin{array}{l}\text { Residential rehabilitation treatment program (RRTP) } \\
\text { aftercare - Individual }\end{array}$ \\
\hline 589 & Non-active duty sexual trauma \\
\hline 590 & $\begin{array}{l}\text { Community outreach homeless Veterans by staff } \\
\text { other than HCHV and RRTP }\end{array}$ \\
\hline 591 & Incarcerated Veterans re-entry \\
\hline 592 & Veterans justice outreach \\
\hline 593 & $\begin{array}{l}\text { Residential rehabilitation treatment program (RRTP) } \\
\text { outreach services }\end{array}$ \\
\hline 594 & RRTP aftercare - Community \\
\hline 595 & RRTP aftercare - VA \\
\hline 596 & RRTP admission screening services \\
\hline 597 & Telephone/RRTP \\
\hline 598 & RRTP pre-admission - Individual \\
\hline 599 & RRTP pre-admission - Group \\
\hline
\end{tabular}


Table 5. Current Procedural Terminology (CPT) Codes for Psychotherapy

\begin{tabular}{|c|c|}
\hline CPT codes & Description \\
\hline 90804 & Outpatient - individual psychotherapy $20-30 \mathrm{~min}$ \\
\hline 90805 & Outpatient - individual psychotherapy $20-30 \mathrm{~min}$ with medical management \\
\hline 90806 & Outpatient - individual psychotherapy $45-50 \mathrm{~min}$ \\
\hline 90807 & Outpatient - individual psychotherapy $45-50 \mathrm{~min}$ with medical management \\
\hline 90808 & Outpatient - individual psychotherapy $75-80 \mathrm{~min}$ \\
\hline 90809 & Outpatient - individual psychotherapy $75-80 \mathrm{~min}$ with medical management \\
\hline 90810 & Outpatient - interactive psychotherapy $20-30 \mathrm{~min}$ \\
\hline 90811 & Outpatient - interactive psychotherapy $20-30 \mathrm{~min}$ with medical management \\
\hline 90812 & Outpatient - interactive psychotherapy $45-50 \mathrm{~min}$ \\
\hline 90813 & Outpatient - interactive psychotherapy $45-50 \mathrm{~min}$ with medical management \\
\hline 90814 & Outpatient - interactive psychotherapy $75-80 \mathrm{~min}$ \\
\hline 90815 & Outpatient - interactive psychotherapy $75-80 \mathrm{~min}$ with medical management \\
\hline 90816 & Inpatient - individual psychotherapy $20-30 \mathrm{~min}$ \\
\hline 90817 & Inpatient - individual psychotherapy $20-30 \mathrm{~min}$ with medical management \\
\hline 90818 & Inpatient - individual psychotherapy $45-50 \mathrm{~min}$ \\
\hline 90819 & Inpatient - individual psychotherapy $45-50$ min with medical management \\
\hline 90821 & Inpatient - individual psychotherapy $75-80 \mathrm{~min}$ \\
\hline 90822 & Inpatient - individual psychotherapy $75-80$ min with medical management \\
\hline 90823 & Inpatient - interactive psychotherapy $20-30 \mathrm{~min}$ \\
\hline 90824 & Inpatient - interactive psychotherapy $20-30 \mathrm{~min}$ with medical management \\
\hline 90826 & Inpatient - interactive psychotherapy $45-50 \mathrm{~min}$ \\
\hline 90827 & Inpatient - interactive psychotherapy $45-50 \mathrm{~min}$ with medical management \\
\hline 90828 & Inpatient - interactive psychotherapy $75-80 \mathrm{~min}$ \\
\hline 90829 & Inpatient - interactive psychotherapy $75-80$ min with medical management \\
\hline 90845 & Psychoanalysis \\
\hline 90847 & Family psychotherapy (conjoint psychotherapy) (with patient present) \\
\hline 90849 & Multiple-family group psychotherapy \\
\hline 90853 & Group psychotherapy (other than of a multiple-family group) \\
\hline 90857 & Interactive group psychotherapy \\
\hline 90875 & Individual psychological therapy incorporating biofeedback, $30 \mathrm{~min}$ \\
\hline 90876 & Individual psychological therapy incorporating biofeedback, $45 \mathrm{~min}$ \\
\hline 90801 & Psychiatric diagnostic evaluation \\
\hline 90802 & Interactive psychiatric diagnostic evaluation \\
\hline 90870 & Electroconvulsive therapy, single seizure \\
\hline 90871 & Electroconvulsive therapy, multiple seizure \\
\hline
\end{tabular}

